\title{
FATAL TRAFFIC ACCIDENTS- A REVIEW ON THE CAUSES OF MORTALITY IN IRAN
}

\author{
Seyed Mohammad Reza Esmaeilnejad Ganji ${ }^{1}$, Seyed Mokhtar Esmaeilnejad Ganji²
}

1MD, Boston University School of Medicine, Boston, U. S. A.

${ }^{2}$ Associate Professor, Department of Orthopaedics, Clinical Research Development Center, Shahid Beheshti Hospital, Babol University of Medical Sciences, Babol, Iran.

\begin{tabular}{l}
\hline ABSTRACT \\
BACKGROUND \\
Traffic accidents have remarkably had negative impacts on the patient's life and health systems in Iran and has remained among \\
the most important causes of morality. In this article, we aimed to review the causes of traffic accidents-related deaths in Iran.
\end{tabular}

\section{MATERIALS AND METHODS}

The databases PubMed, Scopus, Web of Sciences were searched using MeSH keywords of "accidents" and "morality" and "Iran". We also searched the Iranian databases, such as Scientific Information Database and Magiran, using the Persian equivalent of the keywords. The articles which reported causes of traffic accident mortality and published from inception to 2018 were included in this review.

\section{RESULTS}

Finally, 17 articles were included and reviewed. Six main causes of death were identified through reviewing the papers. There were variations in the rate of mortality causes between different regions. Head trauma was the most common cause of death reported in the studies, with a rate between $38 \%$ and $72.4 \%$. Other mortality causes included bleeding (1.25-32.8\%), burns (1-2\%), central nervous system injury (1.9- 61.8\%), multiple fractures (6.3- 47.5\%) and multiple trauma (12.6-35\%). Undetermined causes were responsible for $0.8-9.8 \%$ of traffic accident mortality.

\section{CONCLUSION}

According to the results, head trauma was the most common cause of traffic-related mortality in Iran. Altogether, to reduce the rate of road traffic accidents and road traffic accidents related deaths, it is necessary to increase public knowledge regarding risks of unsafe driving, encourage people to use seatbelt and helmet, implement the traffic laws more seriously, raise the road safety standards and improve the emergency services.

\section{KEYWORDS}

Accidents, Mortality, Cause of Death.

HOW TO CITE THIS ARTICLE: Ganji SMRE, Ganji SME. Fatal traffic accidents- a review on the causes of mortality in Iran. J. Evolution Med. Dent. Sci. 2018;7(49):5323-5327, DOI: 10.14260/jemds/2018/1177

\section{BACKGROUND}

Trauma is still among the main causes of mortality and morbidity in the world and Iran is one of the countries in which trauma has negatively had enormous effect on the patient's life and health systems.(1-3) Injuries account for approximately $28 \%$ of the disability adjusted life years lost $(21,572)$ in Iran.(4) Road traffic accident, as one of the most important injuries, leads to death of 1.25 million people in the world every year, according to the World Health Organization (WHO) report. This rate is nearly 18, 000 people in Iran.(5) It is stated that about 1.5 million vehicles are annually added in this country, as the ratio of vehicle to people is $4: 1$ which is highest among the Eastern Mediterranean countries.(6,7) Traffic accidents have considerably more serious outcomes in developing countries versus developed counties and the WHO and World Bank estimate that rate of fatal traffic accident will increase even by $147 \%$ within the next two decades in low and middle income countries.(8-10)

'Financial or Other Competing Interest': None.

Submission 25-10-2018, Peer Review 18-11-2018,

Acceptance 25-11-2018, Published 03-12-2018.

Corresponding Author:

Dr. Seyed Mokhtar Esmaeilnejad Ganji,

Department of Orthopaedics,

Babol University of Medical Sciences,

Ganjafrooz Street, Babol, Iran.

E-mail: smsnganji20@gmail.com

DOI: $10.14260 /$ jemds/2018/1177
Thus, it is necessary to consider traffic crashes as priorities in such communities, such as Iran. In the present study, we aimed to review the causes of death due to traffic accidents in Iran. The obtained data will be useful for the relevant authorities to plan and improve health promotion interventions based on the identified causes of traffic accidents-related mortality.

\section{MATERIALS AND METHODS}

We searched the literatures from electronic databases PubMed, Scopus, Web of Sciences using MeSH keywords of "accidents" and "morality" and "Iran". We also searched the Iranian databases, such as Scientific Information Database and Magiran, using the Persian equivalent of the mentioned keywords. The literature published from inception to 2018 was considered for retrieval and discussion. By the way, the studies stated the causes of traffic accident mortality were included. Full-text of the relevant articles were completely reviewed and the necessary data were extracted.

\section{RESULTS}

Six main causes of death were identified through reviewing the seventeen articles, including bleeding, burns, central nervous system injury, head trauma, multiple fractures, and multiple trauma. Other causes were reported, as well as undetermined causes. There were variations in the frequency of mortality causes between different regions (Table 1). 


\begin{tabular}{|c|c|c|c|c|c|}
\hline Study Place & Author & Publication Date & Study Date & Death Nos. & Cause Rate (\%) \\
\hline \multicolumn{6}{|c|}{ Bleeding } \\
\hline Amol & Nazari(11) & 2010 & 2007 & 125 & 32 \\
\hline East Azerbaijan & Sadeghi-Bazargani(12) & 2018 & 2006-2014 & 7818 & 8.6 \\
\hline East Azerbaijan & Sadeghi-Bazargani(13) & 2018 & 2006-2016 & 1357 & 32.8 \\
\hline Fars & Heydari(14) & 2013 & $2009-2011$ & 3642 & 13.2 \\
\hline Fars & Hasanzadeh(15) & 2014 & $2004-2010$ & 5840 & 5 \\
\hline Fars & Rakhshani(16) & 2016 & 2011-2012 & 1668 & 12 \\
\hline Kerman & Ghadipasha(17) & 2015 & - & 1185 & 7.8 \\
\hline Nationwide & Montazeri(18) & 2003 & $1999-2000$ & 15045 & 10 \\
\hline Qom & Parvaresh Masoud(19) & 2017 & 2014 & 80 & 1.25 \\
\hline Semnan & Hasani(20) & 2016 & 2011 & 331 & 8.5 \\
\hline Tabriz & Gholipour(21) & 2016 & $2013-2014$ & 160 & 28.1 \\
\hline Tehran & Sanaei-Zadeh(22) & 2002 & $2000-2001$ & 2128 & 11.1 \\
\hline Yazd & Moharamzad(23) & 2008 & 2006 & 251 & 16 \\
\hline Yazd & Fallahzadeh(24) & 2011 & $2003-2008$ & 2565 & 11.4 \\
\hline \multicolumn{6}{|c|}{ Burns } \\
\hline East Azerbaijan & Sadeghi-Bazargani(13) & 2018 & $2006-2016$ & 1357 & 2 \\
\hline Kermanshah & Hamzeh $^{(25)}$ & 2016 & 2004-2013 & 5110 & 1 \\
\hline \multicolumn{6}{|c|}{ Central Nervous System Injury } \\
\hline Tabriz & Gholipour(21) & 2016 & 2013-2014 & 160 & 60.6 \\
\hline Tehran & Sanaei-Zadeh(22) & 2002 & $2000-2001$ & 2128 & 1.9 \\
\hline Yazd & Moharamzad(23) & 2008 & 2006 & 251 & 61.8 \\
\hline \multicolumn{6}{|c|}{ Head Trauma } \\
\hline Amol & Nazari(11) & 2010 & 207 & 125 & 57.6 \\
\hline East Azerbaijan & Sadeghi-Bazargani(12) & 2018 & 2006-2014 & 7818 & 62.5 \\
\hline East Azerbaijan & Sadeghi-Bazargani(13) & 2018 & $2006-2016$ & 1357 & 81 \\
\hline Fars & Heydari $(26)$ & 2012 & $2009-2010$ & 2345 & 70.8 \\
\hline Fars & Heydari(14) & 2013 & $2009-2011$ & 3642 & 72.4 \\
\hline Fars & Hasanzadeh(15) & 2014 & $2004-2010$ & 5840 & 38 \\
\hline Fars & Rakhshani(16) & 2016 & $2011-2012$ & 1668 & 72 \\
\hline Kerman & Ghadipasha(17) & 2015 & - & 1185 & 63.4 \\
\hline Kermanshah & Hamzeh(25) & 2016 & $2004-2013$ & 5110 & 69.9 \\
\hline Mazandaran & Janmohammadi(27) & 2009 & $2002-2004$ & 348 & 50.6 \\
\hline Nationwide & Montazeri(18) & 2003 & $1999-2000$ & 15045 & 66 \\
\hline Qom & Parvaresh Masoud(19) & 2017 & 2014 & 80 & 45 \\
\hline Semnan & Hasani(20) & 2016 & 2011 & 331 & 44.1 \\
\hline Tehran & Sanaei-Zadeh(22) & 2002 & $2000-2001$ & 2128 & 49.8 \\
\hline Yazd & Fallahzadeh(24) & 2011 & $2003-2008$ & 2565 & 70.2 \\
\hline \multicolumn{6}{|c|}{ Multiple Fractures } \\
\hline Amol & Nazari(11) & 2010 & 2007 & 125 & 9.6 \\
\hline East Azerbaijan & Sadeghi-Bazargani(12) & 2018 & 2006-2014 & 7818 & 14 \\
\hline East Azerbaijan & Sadeghi-Bazargani(13) & 2018 & $2006-2016$ & 1357 & 6.3 \\
\hline Fars & Heydari(14) & 2013 & $2009-2011$ & 3642 & 11.6 \\
\hline Fars & Hasanzadeh(15) & 2014 & $2004-2010$ & 5840 & 27 \\
\hline Fars & Rakhshani(16) & 2016 & 2011-2012 & 1668 & 12 \\
\hline Kerman & Ghadipasha(17) & 2015 & - & 1185 & 21 \\
\hline Nationwide & Montazeri(18) & 2003 & $1999-2000$ & 15045 & 8 \\
\hline Qom & Parvaresh Masoud(19) & 2017 & 2014 & 80 & 47.5 \\
\hline Semnan & Hasani(20) & 2016 & 2011 & 331 & 41 \\
\hline Yazd & Fallahzadeh(24) & 2011 & $2003-2008$ & 2565 & 8.6 \\
\hline \multicolumn{6}{|c|}{ Multiple Trauma } \\
\hline Kermanshah & $\operatorname{Hamzeh}^{(25)}$ & 2016 & $2004-2013$ & 5110 & 12.6 \\
\hline Tehran & Sanaei-Zadeh(22) & 2002 & $2000-2001$ & 2128 & 35 \\
\hline \multicolumn{6}{|c|}{ Not Defined } \\
\hline Amol & Nazari(11) & 2010 & 2007 & 125 & 0.8 \\
\hline East Azerbaijan & Sadeghi-Bazargani(13) & 2018 & 2006-2016 & 1357 & 9.8 \\
\hline Nationwide & Montazeri(18) & 2003 & $1999-2000$ & 15045 & 3 \\
\hline Qom & Parvaresh Masoud(19) & 2017 & 2014 & 80 & 1.25 \\
\hline \multicolumn{6}{|c|}{ Other Causes } \\
\hline East Azerbaijan & Sadeghi-Bazargani(12) & 2018 & 2006-2014 & 7818 & 11.3 \\
\hline East Azerbaijan & Sadeghi-Bazargani(13) & 2018 & 2006-2016 & 1357 & 8.4 \\
\hline East Azerbaijan & Sadeghi-Bazargani(13) & 2018 & 2006-2016 & 1357 & 7 \\
\hline Fars & Heydari $(26)$ & 2012 & $2009-2010$ & 2345 & 29.2 \\
\hline Fars & Heydari(14) & 2013 & $2009-2011$ & 3642 & 6.6 \\
\hline Fars & Hasanzadeh(15) & 2014 & $2004-2010$ & 5840 & 30 \\
\hline
\end{tabular}




\begin{tabular}{|c|c|c|c|c|c|}
\hline Kermanshah & Hamzeh $^{(25)}$ & 2016 & $2004-2013$ & 5110 & 9 \\
\hline Kermanshah & Hamzeh $^{(25)}$ & 2016 & $2004-2013$ & 5110 & 7.5 \\
\hline Nationwide & Montazeri(18) $^{(18)}$ & 2003 & $1999-2000$ & 15045 & 13 \\
\hline Tehran & Sanaei-Zadeh $(22)$ & 2002 & $2000-2001$ & 2128 & 0.6 \\
\hline Yazd & Fallahzadeh(24) & 2011 & $2003-2008$ & 2565 & 6.1 \\
\hline \multicolumn{2}{|l}{} \\
\hline
\end{tabular}

\section{Bleeding}

Thirteen articles from 9 different regions and 1 national study reported the rate of accident mortality for bleeding between 1.25\% (Qom)(19) and 32.8\% (East Azerbaijan).(13) Bleeding or haemorrhage is not unexpected in the traffic accidents, but based on severity and degree, it has its own priority for management. Bleeding can represent as internal and external types following trauma. Internal bleeding can occur in different organs and parts of the body, such as head (Subarachnoid or subdural haemorrhage), kidney, liver, and retroperitoneal space. In the study by Ghadipasha et al.(17) In Kerman, internal bleeding was responsible for $7.8 \%$ of deaths in 1185 victims. This rate was reported $11.1 \%$ in the study by Sanaei-Zadeh et al.(22) in Tehran, and 8\% in Moharamzad et al.'s study(23) in Yazd. Also, Moharamzad et al.(23) Stated that $8 \%$ of 251 people died due to lower limb haemorrhage.

Early hypotension and haemorrhagic shock can lead to remarkable complications, such as eventual organ failure and the development of infections, including sepsis.(28,29) Prehospital emergency care has a vital role in this regard. Early diagnosis and assessment of bleeding severity, rapid primary intervention in the first hours of traffic accident and then transportation of patients from the scene of accident to definitive trauma center care can efficiently decrease risk of mortality and morbidity. Overall, interventions to improve haemostasis in traumatic cases are classified as four phases: A) Prehospital interventions (Control overt haemorrhage, direct pressure, pressure dressing or tourniquet, diagnose and treat occult haemorrhage, stabilization of pelvis and long bone fractures, keep patient warm); (B) Resuscitative phase (Warmed intravenous fluids, hypotensive resuscitation prior to surgical control of haemorrhage, appropriate transfusion of blood and blood products); (C) Operative phase (Surgical control of life-threatening haemorrhage, damage control operations for critically ill patients, appropriate transfusion of blood and blood products); (D) Critical care phase (Effective resuscitation, end-points of tissue perfusion, physiologic support to prevent coagulopathy).(30)

\section{Burns}

Limited data were found regarding burns and their frequency in list of morality causes. One study in East Azerbaijan(13) and one study in Kermanshah(25) reported rates of $2 \%$ and $1 \%$ among 1357 and 5110 deaths for burns, respectively. Previously, Purdue et al.(31) reported a mortality rate of $24.7 \%$ in the United States This rate was $11 \%$ in Bunn et al.'s study.(32)

Despite technical improvements by the automobile industry, burned patients due to traffic crashes have been remained dramatic in clinical routine.(33) Traffic accident burn injuries are typically categorized as three groups: Heat burns, electrical burns, chemical burns. Among them, heat burns are the most frequent type related to traffic accident victims. The first step for management of burns in determination of burn type and its extent.
Thereafter, measures should be taken to decrease victims' pain and potential infection. Simultaneously, fluid therapy containing resuscitation and maintenance needs to be done.

\section{Central Nervous System Injury}

After reviewing the available data, three articles reported variable rates of traffic accident mortality for central nervous system (CNS) injury, from $1.9 \%$ in Tehran(22) to $61.8 \%$ in Yazd.(23) These two were of course related to cervical spinal cord injury.

CNS injury outcomes following traffic crashes depend on place of injury and its severity. Patients may experience different symptoms after CNS traffic injury from the first hours to next times, including headaches, migraines, tingling and numbness. At the scene of accident, we need to think about the spine protection (Especially cervical spine) as a priority. Neck protection can be facilitated with appropriate cervical immobilization devices (e.g., hard collar and tape), if not available, sandbags or rolled-up pieces of clothing can be used. $(34,35)$

\section{Head Trauma}

Head trauma was reported as the most common cause of death in almost all of the included articles. Its rate was between $38 \%$ and $72.4 \%$. A national study by Montazeri et al.(18) Reported a rate of $66 \%$. Head injury was the most frequent cause of death in other countries as well, for instance, $78.7 \%$ in Vietnam,(36) 66.4\% in Karachi, Pakistan,(37) and $48.3 \%$ in Nigeria.(38) Study by Hamzeh et al.(25) Stated a rate of $69.9 \%$, which was higher in drivers $(73.1 \%)$ than in occupants $(71.9 \%)$ and in pedestrians (64.3\%). This difference can be explained by various road user types.

Head trauma and intracranial haemorrhage are closely linked to each other, as the trauma is one of the principle causes of intracranial bleeding.(39) Previous surveys revealed that helmet and seat belt use could provide adequate protection and reduce the severity of head injury and resultant traffic accident mortality by at least $50 \%$.(40) However, use of helmet in Iran is not usual, for example, and two studies from Tehran alluded to its use only by $6 \%$ and $8 \%$ of motorcyclists. $(41,42)$ An investigation from Shiraz reported the total estimated costs of 513 billion Rials (20.7 million USD) by brain trauma deaths resulting from traffic accidents during 2009 to 2013.(43) Altogether, it is highly the necessary measures should be performed to increase public awareness toward importance of helmet and seatbelt use by the relevant authorities and policy-makers. Also, the mandatory seatbelt and helmet laws need to be enforced more seriously.

\section{Multiple Fractures}

Eleven aerticles reported various rates of causalty for multiple fractures between $6.3 \%$ in East Azerbaijan(13) and 47.5\% in Qom.(8) In Moharamzad et al.'s study(23) in Yazd, 
skull base fracture with rate of $10 \%$ and skull vault fracture with rate of $4 \%$ were identified as causes of fatal traffic accidents. An investigation from India reported that near $70 \%$ of the vehicular deaths was related to skull fractures. ${ }^{(44)}$ Fractures were among the most common injuries following traffic accidents in the previous studies. $(45,46)$

To manage fractures, both of non-operative and operative techniques can be used. In non-operative approach, closed reduction and immobilization with casting or splinting are used for the patients whose fractures are displaced or angulated. Blood supply and soft-tissue health are the most important factors in factures healing. Although indications for surgical intervention is determined by the surgeon, some of them include failed non-operative (Closed) management, unstable open fractures, and non-unions or malunions. $(47,48)$

\section{Multiple Trauma, and Other Causes}

Two reports were available on multiple trauma. One study in Kermanshah revealed a rate of $12.6 \%{ }^{(25)}$ and another study in Tehran alluded to a rate of $35 \% .{ }^{(22)}$ A recent systematic review stated that brain trauma is an early cause of death after multiple trauma (up to 24 hours of the injury) and the second frequent cause of death results from thoracic or abdominal injuries.

A survey by Hamzeh et al.(25) Expressed that limb injury was responsible for morality of $7.5 \%$ of victims in Kermanshah. Mixed causes of death were reported by Sadeghi-Bazargani et al. in two articles in East Azerbaijan, with rates of $11.3 \%{ }^{(12)}$ and $8.4 \% .^{(13)} \mathrm{A}$ series of undetermined causes was mentioned in reports from Amol (0.8\%),(11) East Azerbaijan (9.8\%),(13) Qom (1.25\%) and nation (3\%).(19) Others causes of traffic accidents mortality were stated by the researchers in eight studies but without more explanations and details. $(13,22,25,18,26,14,15,24)$

\section{CONCLUSION}

Our results show that head trauma was the most common cause of traffic-related mortality in Iran. Furthermore, bleeding, burns, and multiple fractures were other main causes. To reduce the rate of road traffic accidents and road traffic accidents related deaths, it is necessary to increase public knowledge about risks of unsafe driving, encourage people to use seatbelt and helmet, implement the traffic laws more seriously, raise the road safety standards and improve the emergency services.

\section{REFERENCES}

[1] Haagsma JA, Graetz N, Bolliger I, et al. The global burden of injury: incidence, mortality, disabilityadjusted life years and time trends from the Global Burden of Disease study 2013. Injury Prevention: Journal of the International Society for Child and Adolescent Injury Prevention 2016;22(1):3-18.

[2] Ganji SME, Bahrami M, Poorghaz N, et al. The frequency of road accident injuries among victims admitted to Shahid Beheshti hospital of Babol, Iran in 2010-2012. J Babol Univ Med Sci 2015;17(9):29-33.

[3] Ganji SME, Baghianimoghadam B, Ahangar SK, et al. Epidemiology and patterns of trauma in children. Trauma Monthly 2017;22(4):e34669.
[4] Aghajani HM, Haddadi M, Saadat S. Epidemiological pattern of injuries in Iran: a nationwide review of seven million emergency department admissions. Emergency (Tehran, Iran) 2017;5(1):e10.

[5] World Health Organization. Global Status Report on Road Safety 2015. Italy: WHO, 2015.

[6] Akbari M, Naghavi M, Soori H. Epidemiology of deaths from injuries in the Islamic Republic of Iran. East Mediterr Health J 2006;12(3-4):382-90.

[7] Naghavi M, Akbari M. Epidemiology of injuries resulting from extrinsic causes (accidents) in Islamic Republic of Iran. Tehran: Fekrat Cultural Publishing Institute 2002: p. 1381.

[8] Mohseni M, Janmohammadi N, Zamani M, et al. A survey of non-fatal road traffic accidents in Babol, Northern Iran, 2010-16. Trauma Monthly 2018;26(6):e66513.

[9] Sheikholeslam R, Mohamad A, Mohammad K, et al. Non communicable disease risk factors in Iran. Asia Pac J Clin Nutr 2004;13:S100.

[10] Hazen A, Ehiri JE. Road traffic injuries: hidden epidemic in less developed countries. J Natl Med Assoc 2006;98(1):73-82.

[11] Nazari R, Bijani A, Hosseini FH, et al. Mortality and injury severity in the accident victims referred to the Hefdah Shahrivar hospital of Amol, 2007. Journal of Babol University of Medical Sciences 2011;13(1):7681.

[12] Sadeghi-Bazargani H, Samadirad B, Shahedifar N, et al. Epidemiology of road traffic injury fatalities among car users; a study based on forensic medicine data in East Azerbaijan of Iran. Bulletin of Emergency \& Trauma 2018;6(2):146-54.

[13] Sadeghi-Bazargani H, Samadirad B, Moslemi F. A decade of road traffic fatalities among the elderly in north-West Iran. BMC Public Health 2018;18(1):111.

[14] Heydari ST, Hoseinzadeh A, Ghaffarpasand F, et al. Epidemiological characteristics of fatal traffic accidents in Fars province, Iran: a community-based survey. Public Health 2013;127(8):704-9.

[15] Hasanzadeh J, Moradinazar M, Najafi F, et al. Trends of mortality of road traffic accidents in Fars province, Southern Iran, 2004 - 2010. Iranian Journal of Public Health 2014;43(9):1259-65.

[16] Rakhshani T, Rakhshani F, Asadi ZS, et al. Study of the pattern of mortality caused by Traffic Accidents (TAs) in The South of Iran. J Pak Med Assoc 2016;66(6):6449.

[17] Ghadipasha M, Vaghefi SS, Esfeh SK, et al. An annual analysis of clinical diagnosis versus autopsy findings in fatal motor vehicle accident in legal medicine organization of Kerman province, Iran. Journal of Forensic and Legal Medicine 2015;34:164-7.

[18] Montazeri A. Road-traffic-related mortality in Iran: a descriptive study. Public Health 2004;118(2):110-3.

[19] Masoud MP, Asayesh H, Hoseini MHM, et al. Epidemiology of road accident death in Qom province, 2014 (Iran). Qom Univ Med Sci J 2017;11(8):94-100.

[20] Hasani J, Nazari SSH, Ghadirzadeh M, et al. An epidemiological study of fatal road traffic accidents in Semnan province (Iran), in 2011. Koomesh 2016;17(2):304-11. 
[21] Gholipour C, Rad BS, Vahdati SS, et al. Assessment of causes of preventable deaths in pre-hospital settings. Erciyes Med Journal 2016;38(2):66-9.

[22] Sanaei-Zadeh H, Vahabi R, Nazparvar B, et al. An epidemiological study and determination of causes of traffic accident-related deaths in Tehran, Iran (during 2000-2001). Journal of Clinical Forensic Medicine 2002;9(2):74-7.

[23] Moharamzad Y, Taghipour H, Firoozabadi NH, et al. Mortality pattern according to autopsy findings among traffic accident victims in Yazd, Iran. Zhonghua Chuang Shang Za Zhi: Chinese Journal of Traumatol 2008;11(6):329-34.

[24] Fallahzadeh H, Dehgani A. Epidemiology of road traffic mortality and injuries in Yazd, Iran during 2003-2008. Zhonghua Chuang Shang Za Zhi: Chinese Journal of Traumatol 2011;14(5):293-6.

[25] Hamzeh B, Najafi F, Karamimatin B, et al. Epidemiology of traffic crash mortality in west of Iran in a 9 year period. Zhonghua Chuang Shang Za Zhi Chinese Journal of Traumatol 2016;19(2):70-4.

[26] Heydari ST, Maharlouei N, Foroutan A, et al. Fatal motorcycle accidents in Fars Province, Iran: a community-based survey. Zhonghua Chuang Shang Za Zhi: Chinese Journal of Traumatol 2012;15(4):222-7.

[27] Janmohammadi N, Pourhossein M, Hashemi SR. Pattern of motorcyclist's mortality in Mazandran Province, Northern Iran. Iranian Red Crescent Medical Journal 2009;11(1):81-4.

[28] Franklin GA, Boaz PW, Spain DA, et al. Prehospital hypotension as a valid indicator of trauma team activation. The Journal of Trauma 2000;48(6):1034-7.

[29] Heckbert SR, Vedder NB, Hoffman W, et al. Outcome after hemorrhagic shock in trauma patients. The Journal of Trauma 1998;45(3):545-9.

[30] Kauvar DS, Wade CE. The epidemiology and modern management of traumatic hemorrhage: US and international perspectives. Crit Care 2005;9(Suppl 5):S1-S9.

[31] Purdue GF, Hunt JL, Layton TR, et al. Burns in motor vehicle accidents. The Journal of Trauma 1985;25(3):216-9.

[32] Bunn TL, Slavova S, Robertson M. Crash and burn? Vehicle, collision and driver factors that influence motor vehicle collision fires. Accident Analysis and Prevention 2012;47:140-5.

[33] Brand S, Otte D, Stübig T, et al. Mechanisms of motor vehicle crashes related to burns - an analysis of the German In Depth Accident Study (GIDAS) database. Burns: Journal of the International Society for Burn Injuries 2013;39(8):1535-40.

[34] Hadley MN, Walters BC, Grabb PA, et al. Cervical spine immobilization before admission to the hospital. Neurosurgery 2002;50(Suppl 3):S7-S17.
[35] Hostler D, Colburn D, Seitz SR. A comparison of three cervical immobilization devices. Prehosp Emerg Care 2009;13(2):256-60.

[36] Ngo AD, Rao C, Hoa NP, et al. Road traffic related mortality in Vietnam: evidence for policy from a national sample mortality surveillance system. BMC Public Health 2012;12:561.

[37] Mirza FH, Hassan Q, Jajja N. An autopsy-based study of death due to road traffic accidents in metropolis of Karachi. The Journal of the Pakistan Medical Association 2013;63(2):156-60.

[38] Osime OC, Elusoji SO, Eboreime O. Pattern and outcome of road traffic accidents in a suburban community in Nigeria. AJOL 2009;8(1):36-43.

[39] Rajeev V. Pattern of intracranial haemorrhages in fatal road traffic accidents. J Evolution Med Dent Sci 2017;6(62):4564-8.

[40] Vafaee-Najar A, Esmaeili H, Ibrahimipour $\mathrm{H}$, et al. Motorcycle fatal accidents in Khorasan Razavi Province, Iran. Iranian Journal of Public Health 2010;39(2):95-101.

[41] Zargar M, Khaji A, Karbakhsh M. Pattern of motorcycle-related injuries in Tehran, 1999 to 2000: a study in 6 hospitals. East Mediterr Health J 2006;12(12):81-7.

[42] Roudsari BS, Sharzei K, Zargar M. Sex and age distribution in transport-related injuries in Tehran. Accident Analysis and Prevention 2004;36(3):391-8.

[43] Kavosi Z, Jafari A, Hatam N, et al. The economic burden of traumatic brain injury due to fatal traffic accidents in Shahid Rajaei Trauma hospital, Shiraz, Iran. Archives of Trauma Research 2015;4(1):e22594.

[44] Kumar A, Lalwani S, Agrawal D, et al. Fatal road traffic accidents and their relationship with head injuries: an epidemiological survey of five years. Indian Journal of Neurotrauma (IJNT) 2008;5(2):63-7.

[45] Ganveer G, Tiwari RR. Injury pattern among non-fatal road traffic accident cases: a cross-sectional study in Central India. Indian J Med Sci 2005;59(1):9-12.

[46] Pan RH, Chang NT, Chu D, et al. Epidemiology of orthopedic fractures and other injuries among inpatients admitted due to traffic accidents: a 10-year nationwide survey in Taiwan. Article ID 637872, Scientific World Journal 2014;2014: p. 7.

[47] Bone L, Bucholz R. The management of fractures in the patient with multiple trauma. J Bone Joint Surg Am 1986;68(6):945-9.

[48] Witt CE, Bulger EM. Comprehensive approach to the management of the patient with multiple rib fractures: a review and introduction of a bundled rib fracture management protocol. Trauma Surgery \& Acute Care Open 2017;2(1):e000064. 